Mots. Les langages du politique

$72 \mid 2003$

La ville, entre dire et faire

Bibliographie de lexicologie socio-politique. Années 1998-2003

Philippe T. Cong Huyen Nu, Pierre Fiala et Maurice Tournier

\title{
OpenEdition
}

Journals

Édition électronique

URL : https://journals.openedition.org/mots/6783

DOI : $10.4000 /$ mots. 6783

ISSN : 1960-6001

Éditeur

ENS Éditions

Édition imprimée

Date de publication : 1 juillet 2003

Pagination : 183-186

ISBN : 2-84788-034-8

ISSN : 0243-6450

Référence électronique

Philippe T. Cong Huyen Nu, Pierre Fiala et Maurice Tournier, «Bibliographie de lexicologie socio-

politique. Années 1998-2003», Mots. Les langages du politique [En ligne], 72 | 2003, mis en ligne le 29 avril 2008, consulté le 29 avril 2022. URL : http://journals.openedition.org/mots/6783 ; DOI : https:// doi.org/10.4000/mots.6783 


\section{Bibliographie de lexicologie socio-politique Années 1998-2003}

AGAMBEN G., 2002, Moyens sans fins. Notes sur la politique, Paris, Payot et Rivages, $153 \mathrm{p}$.

AMEY P., 2002, “"L'énonciation profane” dans le débat sur l'énergie nucléaire en Suisse», Langage et société, 100, p. 81-106.

ANGENOT M., 2000, Colins et le socialisme rationnel, Canada, Presses de l'université de Montréal, $192 \mathrm{p}$.

AZÉMA J.-P., BÉDARIDA F. et al., 1995, 1938-1948. Les années de tourmente, de Munich à Prague. Dictionnaire critique, Paris, Flammarion, 1137 p.

BECKER A., «1914-1918, le discours de guerre du monde religieux en France», dans d'Almeida F. (dir.), 2001, L'éloquence politique en France et en Italie de 1870 à nos jours, Rome, École française de Rome, p. 119- 127

BEGUEC G. Le, «L'éloquence française entre juridique et politique (19201945)», dans d'Almeida F. (dir.), 2001, L'éloquence politique en France et en Italie de 1870 à nos jours, Rome, École française de Rome, p. 131-142.

BLONDIAUX L., REYNIE D. (dir.), 2002, «L'opinion publique. Perspectives anglo-saxonnes », Hermès, 31, 286 p.

BRANCA S. (dir.), 2001, L'institution des langues, Paris, Éditions de la Maison des sciences de l'homme, $239 \mathrm{p}$.

BURRIN P., 2000, Fascisme, nazisme, autoritarisme, Paris, Le Seuil, 315 p.

COFFEN B., 2002, Histoire culturelle des pronoms d'adresse. Vers une typologie des systèmes allocutoires dans les langues romanes, Paris-Genève, Champion-Slatkine, $320 \mathrm{p}$.

DANBLON E., 2002, Rhétorique et rationalité. Essai sur l'émergence de la critique et de la persuasion, Bruxelles, Éditions de l'université de Bruxelles, $276 \mathrm{p}$.

DEBRAY R., 1997, Transmettre, Paris, Odile Jacob, 203 p.

DÉTRIE C., 2001, Du sens dans le processus métaphorique, Paris, Honoré Champion, $306 \mathrm{p}$. 
DÉTRIE C., SIBLOT P., VÉRINE B., 2001, Termes et concepts pour l'analyse du discours. Une approche praxématique, Paris, Honoré Champion, $416 \mathrm{p}$.

DIECKHOFF A., 2002, La nation dans tous ses États. Les identités nationales en mouvement, Paris, Flammarion, $354 \mathrm{p}$.

DROIXHE D., 2002, L'étymon des dieux. Mythologie gauloise, archéologie et linguistique à l'âge classique, Paris, Droz-Champion, $320 \mathrm{p}$.

FARINA A., 2001, Dictionnaires de langue française du Canada. Lexicographie et société au Québec, Paris, Honoré Champion, 448 p.

GALlY M., JOURDE M. (dir.), 1995, L'inscription du regard. Moyen Âge Renaissance, Fontenay, ENS Éditions (coll. «Signes»), 372 p.

GALLY M., JOURDE M. (dir.), 1999, Par la vue et par l'ouie. Littérature du Moyen Âge et de la Renaissance, Lyon, ENS Éditions (coll. «Signes»), 204 p.

GOETSCHEL P., LOYER E., 2002, Histoire culturelle de la France de la Belle Époque à nos jours, Paris, A. Colin, $252 \mathrm{p}$.

GUILHAUMOU J., 2001, «De la raison ethnographique à la raison discursive: les récits de vie dans le champ de l'exclusion», dans Terrenoire J.-P. (dir.), $L a$ responsabilité des scientifiques, Paris, L'Harmattan, p. 277-292.

GUILHAUMOU J., 2001, "L'histoire des concepts: le contexte historique en débat», Annales. Histoire, sciences sociales, mai-juin, p. 685-698.

GUILHAUMOU J., 2001, «Sieyès et le moi. De la dignité sociale à la duperie mondaine», dans Giovannoni A. (dir.), Les figures de la duperie de soi, Paris, Kimé, p. 43-62.

HÉBERT L., 2001, Introduction à la sémantique des textes, Paris, Honoré Champion, $240 \mathrm{p}$.

JANSEN S., 2001, «Le style d'un avocat en politique: Pierre Cot», dans d'Almeida F. (dir.), L'éloquence politique en France et en Italie de 1870 à nos jours, Rome, École française de Rome, p. 183-196.

KAUFMANN L., 2002, «L'opinion publique ou la sémantique de la normalité», Langage et société, 100, p. 49-79.

LABBÉ D., MONIÈRE D., 2003, Le discours gouvernemental. Canada, Québec, France (1945-2000), Paris, Champion, 181 p.

LAFON P., 2002, «Les mots de l'espace dans l'expression de la revendication syndicale», dans Mélanges en hommage à Gunnel Engwall, CD-Rom, Universitet Stockholms, Almsqvist \& Wiksells, p. 233-242.

«Langues en contact autour de la Méditerranée: hybridation et emprunts», Langage et société, 99, mars 2002, $150 \mathrm{p}$.

«Le droit de comprendre», 2002, Les Français et leur langue en 2001, Paris, Éditions des Écrivains, 180 p. 
MANNO G., 2002, «La politesse et l'indirection: essai de synthèse », Langage et société, 100, Paris, MSH, p.5-45.

MARTIN-BARBERO J., 2002, Des médias aux médiations. Communication, culture et hégémonie, Paris, CNRS Éditions, $224 \mathrm{p}$.

MATHIEU M.-J., 2002, Extension du féminin. Les incertitudes de la langue, Paris-Genève, Champion-Slatkine, $144 \mathrm{p}$.

MENY Y., SUREL Y., 2000, Par le Peuple, pour le Peuple. Le populisme et les démocraties, Paris, Fayard, $326 \mathrm{p}$.

MONGIN O., 1998, L'après-1989. Les nouveaux langages du politique, Paris, Hachette, $258 \mathrm{p}$.

MORIN G., TARTAKOWSKY D., 2001, «Mise en scène et mise en image de l'éloquence. Les congrès communistes et socialistes : 1936-1946», dans d'Almeida F. (dir.), L'éloquence politique en France et en Italie de 1870 à nos jours, Rome, École française de Rome, p. 169-182.

NICOLET C., 2000, Histoire, nation, république, Paris, Odile Jacob, 342 p.

NOËL A., 2002, Les lieux-dits. Essai d'archéologie verbale. La forêt d'Othe à l'Âge moderne, Paris-Genève, Champion-Slatkine, 288 p.

PERRET P., 2002, Le parler des métiers. Dictionnaire thématique alphabétique, Paris, Laffont, 1175 p.

PIRES M., 2001, «Les abréviations des titres de civilité en français. Prescriptions et usages », dans Quemada B. (dir.), Cahiers de lexicologie, 79, 232 p.

PRUVOST J., GUILPAIN-GIRAUD M. (dir.), 2002, Pierre Larousse. Du Grand Dictionnaire au Petit Larousse, Paris-Genève, Champion-Slatkine, 358 p.

QUAGLIARIELLO G., 2001, «L'émigration politique prend la parole: Gaetano Salvemini, conférencier antifasciste», dans d'Almeida F. (dir.), L'éloquence politique en France et en Italie de 1870 à nos jours, Rome, École française de Rome, p. 143-168.

RIOSA A., 2001, «Le patriotisme dans le verbe», dans d'Almeida F. (dir.), L'éloquence politique en France et en Italie de 1870 à nos jours, Rome, École française de Rome, p. 101-117.

RIOUX J.-P., SIRINELLI J.-F., 1998, Histoire culturelle de la France. Vol. 4 : Le temps des masses. Le $20^{e}$ siècle, Paris, Le Seuil, 400 p.

RODOTA S., 1999, La démocratie électronique. De nouveaux concepts et expériences politiques (traduction française de J. Guyot), Rennes, Apogée, 192 p.

ROGER A., 2001, Les grandes théories du nationalisme, Paris, Armand Colin, 224 p.

ROUSSEAU R.-L., 2000, Le langage des couleurs (1980), réédition, Saint-Jean de Braye, Éd. Dangles, 270 p. 
SULLET-NYLANDER F., 2002, «Jeux de mots des titres de presse et polyphonie», dans Mélanges publiés en hommage à Gunnel Engwall, CD-Rom, Universitet Stockholms, Almsqvist \& Wiksells, p. 295-302.

TAGUIEFF P.-A., 2002, L'illusion populiste. De l'archaïque au médiatique, Paris, Berg international, $182 \mathrm{p}$.

TOURNIER M., 2002, «Quand les mots font image: Lionel Jospin télévisé», dans Mélanges publiés en hommage à Gunnel Engwall, CD-Rom, Universitet Stockholms, Almsqvist \& Wiksells, p. 323-334.

VEGLIANTE J.-C. (dir.), 2001, La traduction-migration (déplacements et transferts culturels Italie-France, $19^{e}-20^{e}$ siècles), Paris, L'Harmattan, 254 p.

WEIL P., 2002, Qu'est-ce qu'un Français? Histoire de la nationalité française depuis la Révolution à nos jours, Paris, Grasset, $401 \mathrm{p}$.

WIEVIORKA O., 2001, «Rhétorique et grand dessein : l'art oratoire du général de Gaulle (1940-1944)», dans d'Almeida F. (dir.), L'éloquence politique en France et en Italie de 1870 à nos jours, Rome, École française de Rome, p. 197-206.

WINOCK M., 1999, Le siècle des intellectuels, Paris, Le Seuil, 928 p.

WIONET C., TUTIN A., 2001, Pour informatiser le «Dictionnaire universel» de Basnage (1702) et de Trévoux (1704); approche théorique et pratique, Paris, Honoré Champion, $128 \mathrm{p}$.

Ph. T. Cong Huyen Nu, P. Fiala, M. Tournier 